The University of Maine

DigitalCommons@UMaine

Vocal Popular Sheet Music Collection

Public domain (may be downloaded in full)

1917

\title{
The Butcher, the Baker, the Candlestick Maker
}

May Singhi Breen

Arranger

Mana-Zucca

Composer

Kaye

Lyricist

Follow this and additional works at: https://digitalcommons.library.umaine.edu/mmb-vp

\section{Recommended Citation}

Breen, May Singhi; Mana-Zucca; and Kaye, "The Butcher, the Baker, the Candlestick Maker" (1917). Vocal Popular Sheet Music Collection. Score 3934.

https://digitalcommons.library.umaine.edu/mmb-vp/3934

This Book is brought to you for free and open access by DigitalCommons@UMaine. It has been accepted for inclusion in Vocal Popular Sheet Music Collection by an authorized administrator of DigitalCommons@UMaine. For more information, please contact um.library.technical.services@maine.edu. 


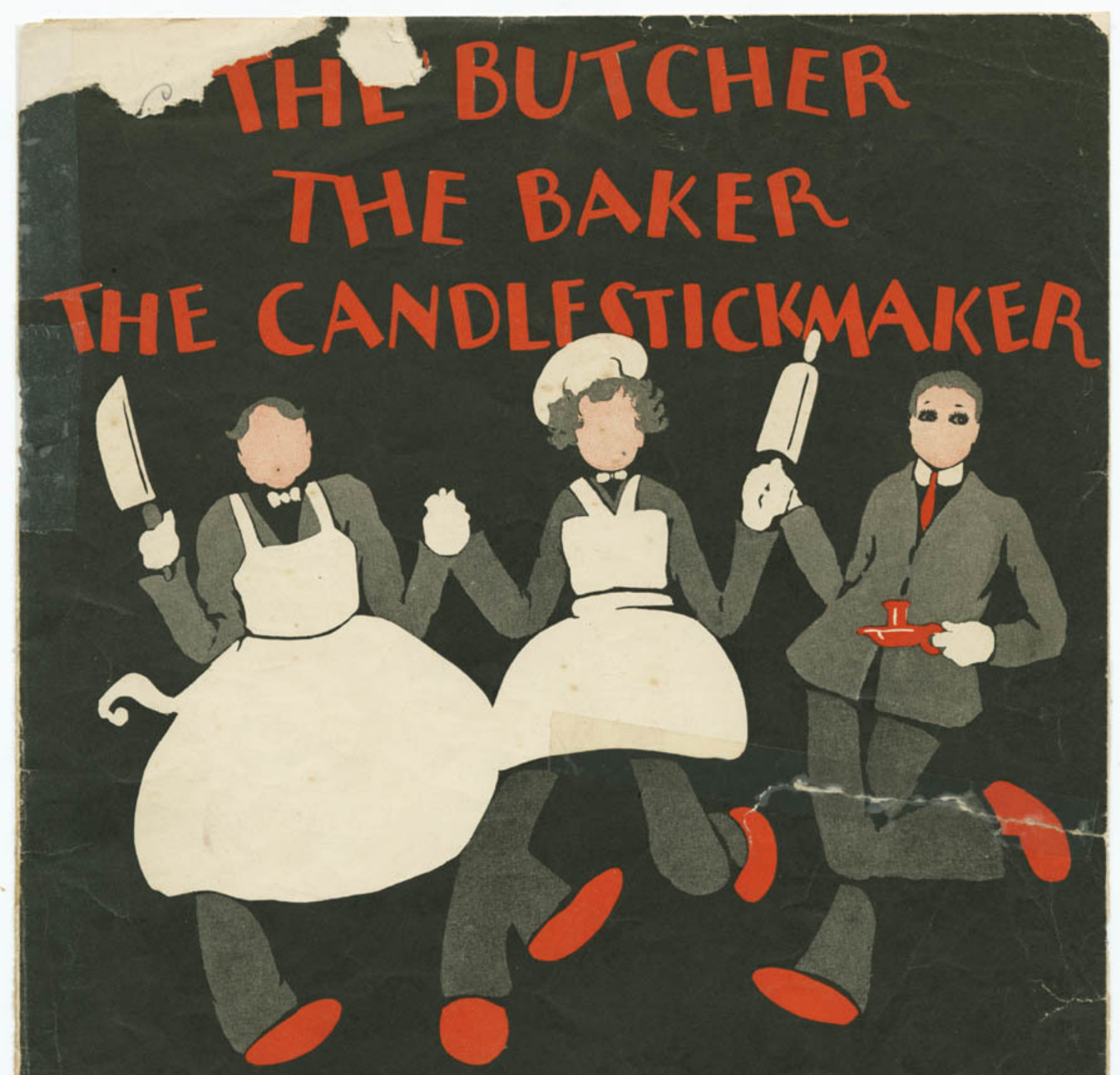

MUSIC BY MANA-ZUCCA-
WITH Up. O12969 ELE
1917 BoT

FEATURED BY

\section{THE GARRICK GAIETIES}

PUBLISHED BY

CASSEL MUSIC COMPANY 25 West 42 nd St NEW YORK
NET RETAIL PRICE $50 \%$ 


\section{cut Lastorer}

The Butcher, The Baker, The Candlestick Maker

BENJ. M. KAYE

With Piano Tune Ukulele

A D FH B

MANA-ZUCCA

Put Ukulele Capo on 1st fret

Moderato

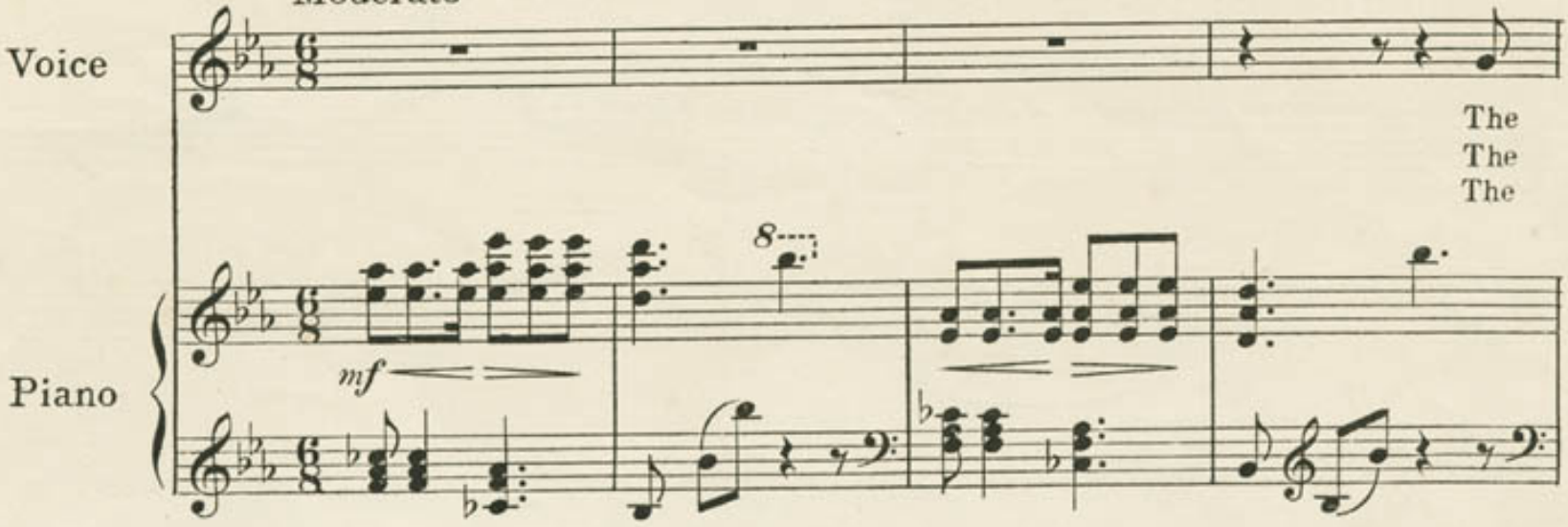

用- - - 缃- - - 册

里

用

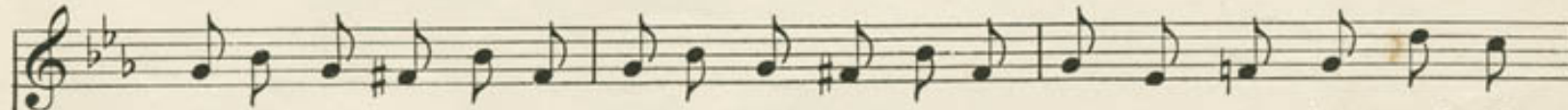

But-cher, the Bak - er, the Can-dle-stick Mak-er, They all were in love with Ma -

But-cher, the Bak - er, the Can-dle-stick Mak - er, They kept up a ver - y high

But-cher, the Bak-er, the Can-dle-stick Mak - er, They all kissed the beau - ti - ful
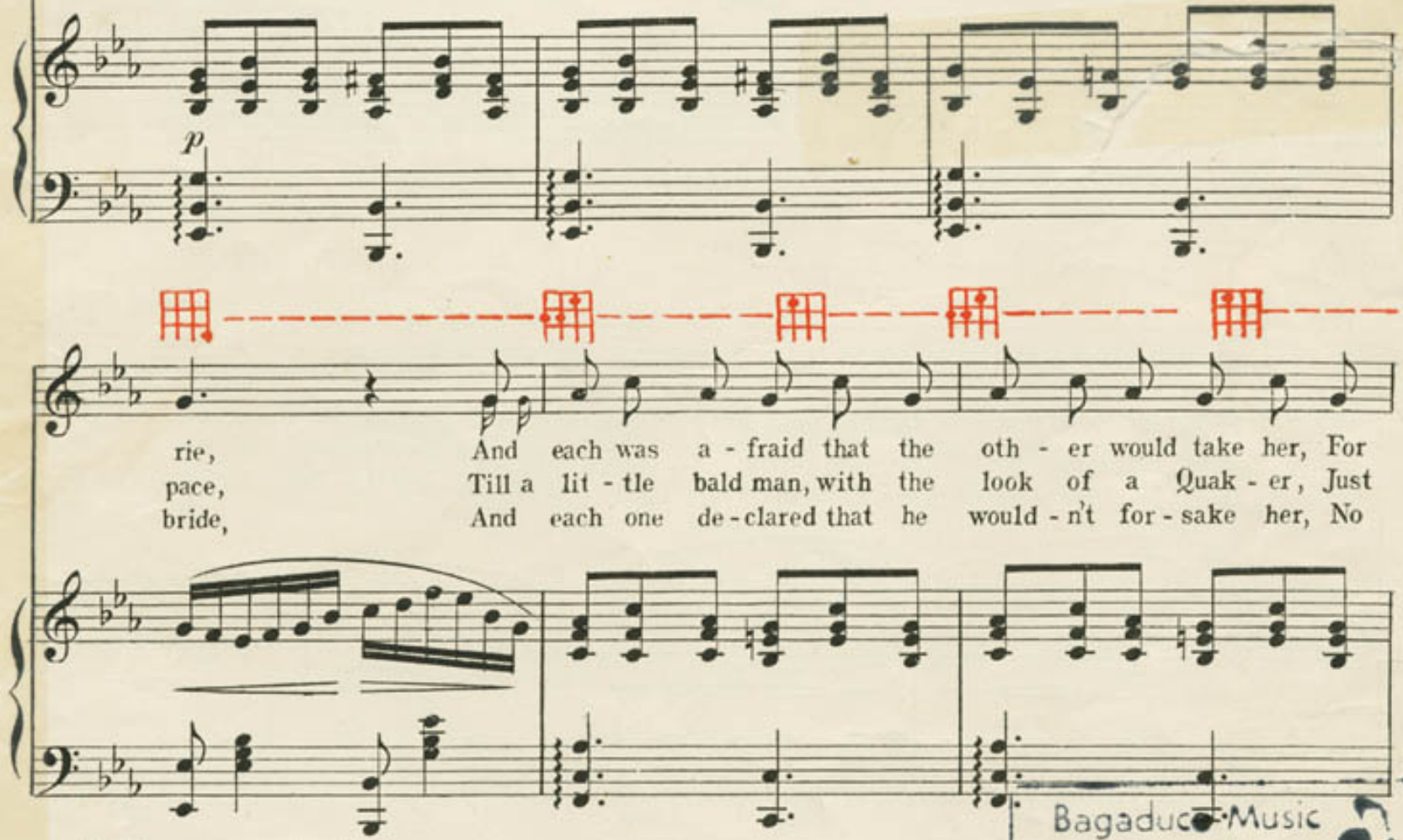

Ukulele accompaniment

By MAY SINGHI BREEN

Copyright. 1917 by Mana Zucca

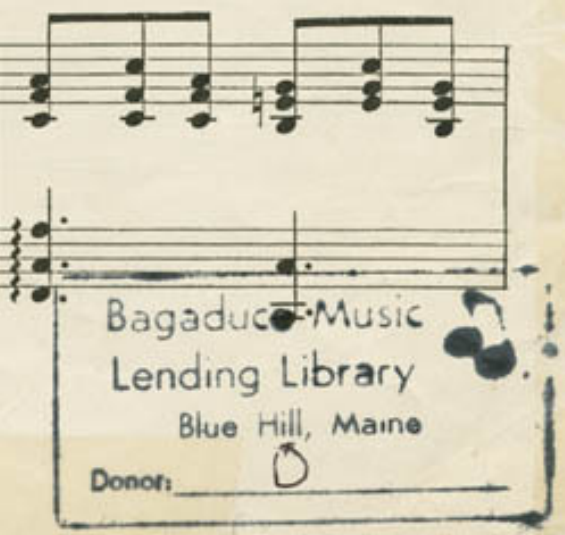




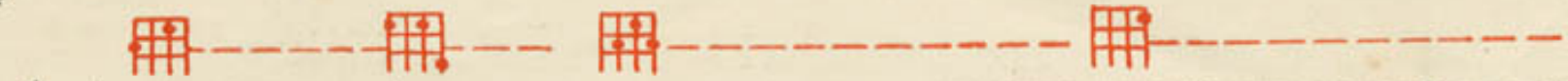
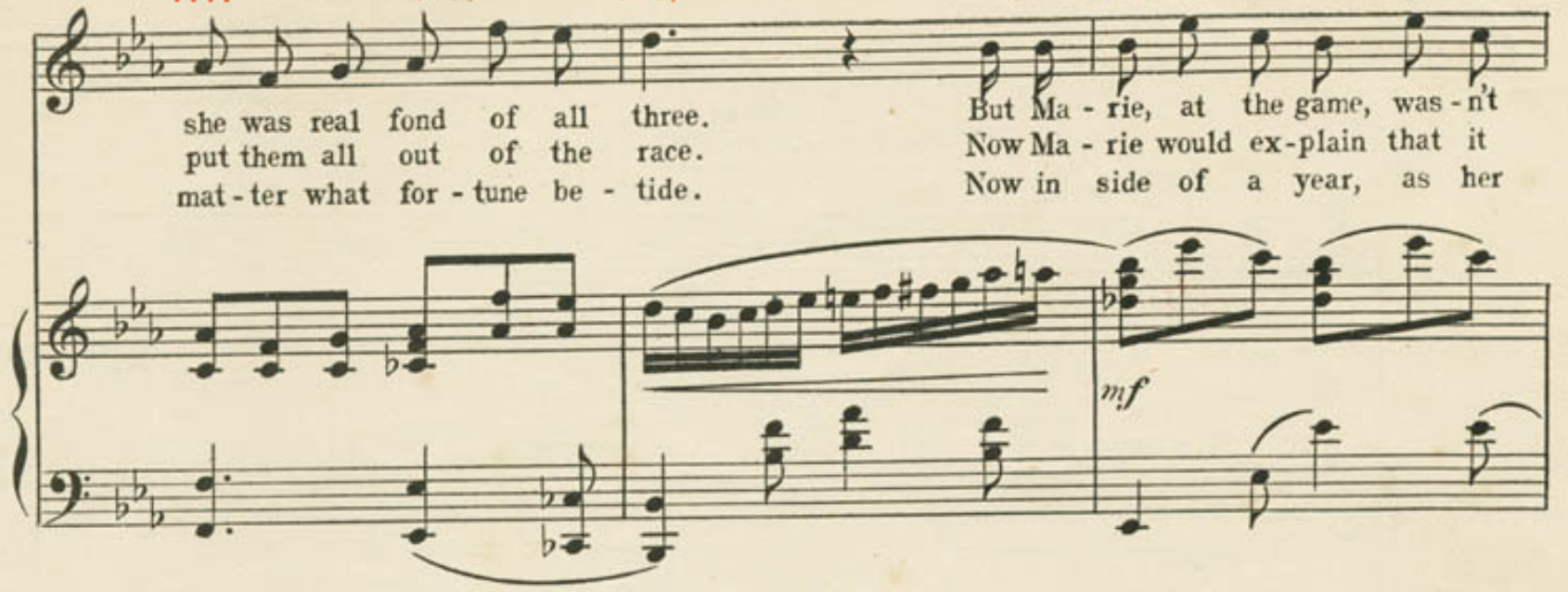

曲

用

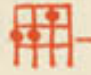

㐿- -
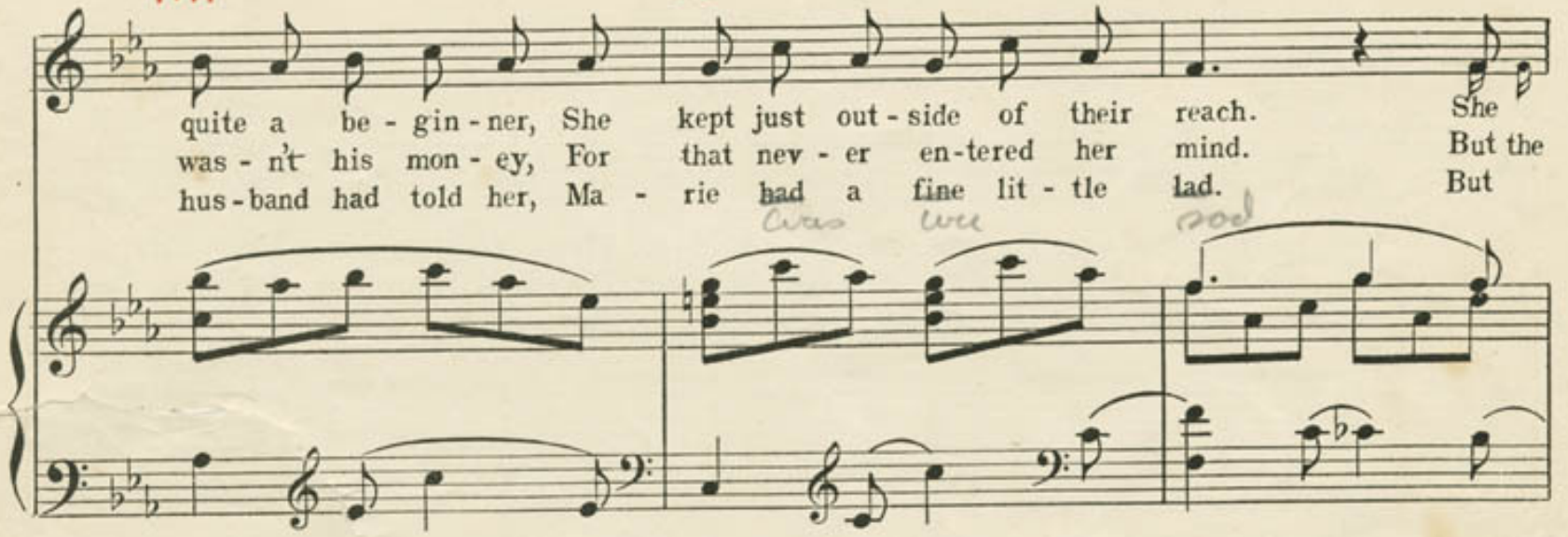

Refrain

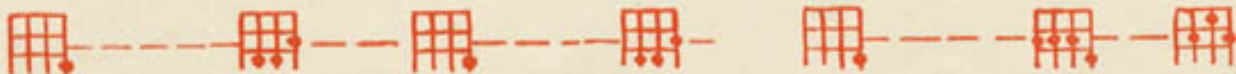

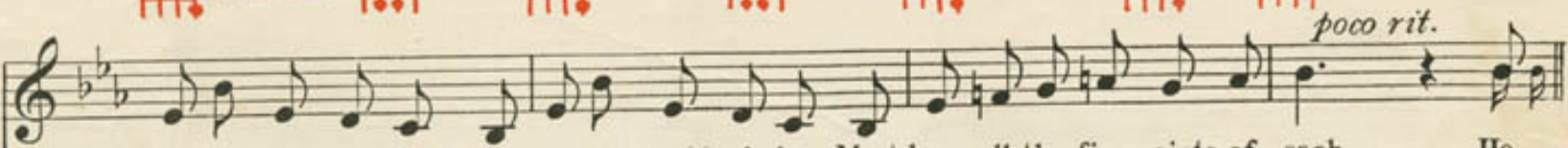

firm-1y de-clared that the manwhowould win her, Must have all the fine points of each.

neigh-borsallthoughther se-lect-ion was fun-ny Or Love was in deed ver - y blind.

ev-'ry-one no-ticed that as he grew ol-der, He did-n't re-sem-ble his Dad.

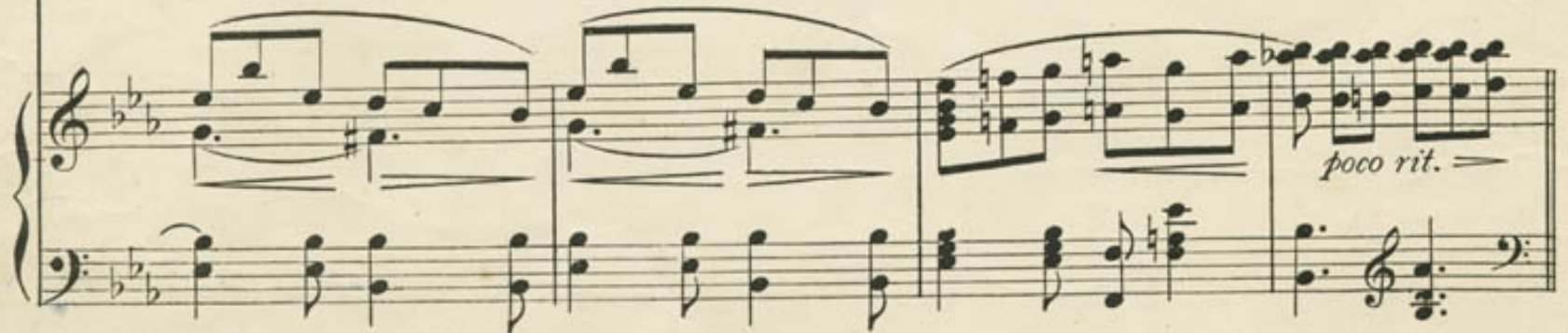



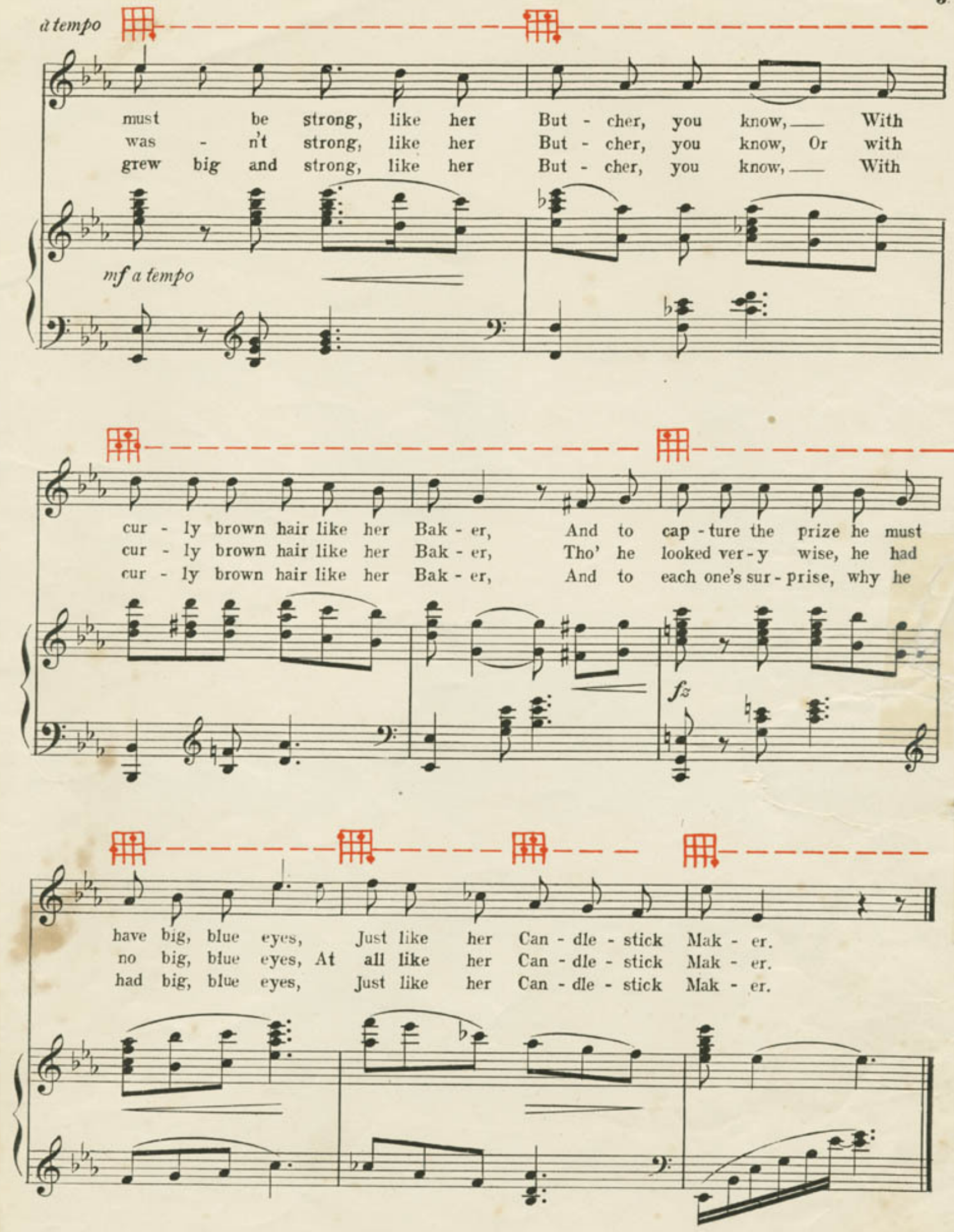